\title{
As Leprolinas "Souza-Araujo" e a sua rápida acção terapêutica nos males perfurantes plantares lepróticos
}

\author{
por \\ H. C. de Souza-Araujo, M. D., Dr. P. H.
}

Em 1941 (Outubro e Novembro) conseguí, após longos anos de tentativas infrutiferas (1928-1941), culturas puras de bacilos ácido-alcool resistentes, semeando pus de lesões fechadas do leproso José (menino de 7 anos, filho de pais leprosos) (1). O isolamento desses bacilos foi obtido em meio de Loewenstein, conseguindo adaptá-los, facilmente, aos meios glicerinados (agar, caldo e batata).

Inoculando, por via subcutânea, emulsões dessas culturas em cobaias e ratos brancos, conseguí recobrar de pus de abcessos ganglionares e pulmonares, produzidos nesses animais, após 2 a 4 semanas de incubação, novas culturas puras, em Loewenstern, idênticas às primitivas. A cultura original tomou o n. ${ }^{\circ}$, amos'ira "Josê", da minha colecção, e as retroculturas "José 1 a", a da cobaia, e "José 1b", a do rato. (Fig. I).

Novas passagens dessas culturas naqueles animais deram igual resultado. Em 1942 consegui, com a colaboração dalguns colegas infectar experimentalmente, em leprosos, ixodídeos e triatomídeos e isolar dos sedimentos destes hematófagos, em meio de LoEWENSTEIN, novas amostras de culturas de baci los ácido-alcool resistentes (2). Tendo adaptado todas as minhas sete culturas originais em meios glicerinados, e verificando que cinco delas produziam espesso véu no caldo glicerinado a 5\% ( $\mathrm{pH}$ 6.8), após alguns dias de incubação a $37^{\circ} \mathrm{C}$., resolví utilizá-las para o preparo de antígenos, destinados a ensaios imunológicos e terapêuticos, na lepra, os quais foram iniciados em Abril de 1943.

Em dezembro de 1943 descreví (3) o método de preparação desses antígenos, aos quais dei o nome de "Leprolinas", por analogia com a de Rost (Burmah, 1904). Fabriquei "Leprolinas" com as três culturas "José", com as cuituras ns. 2,3 e 5 , provenientes de carrapatos e com a n. 6 , isolada de sedimento de Triatoma infestans. 
De 1943 a 1948 foram feitas experiências com essas Leprolinas em vários centros leprológicos deste país e do estrangeiro, sobre as quais já foram publicados mais de quinze trabalhos. Actualmente as "Leprolinas" mais em voga

Fig. I - A cultura "José" n. 1 , e as retroculturas 1 a e $1 \mathrm{~b}$ de cobaia e rato branco, utilizadas na manufactura das Leprolinas.

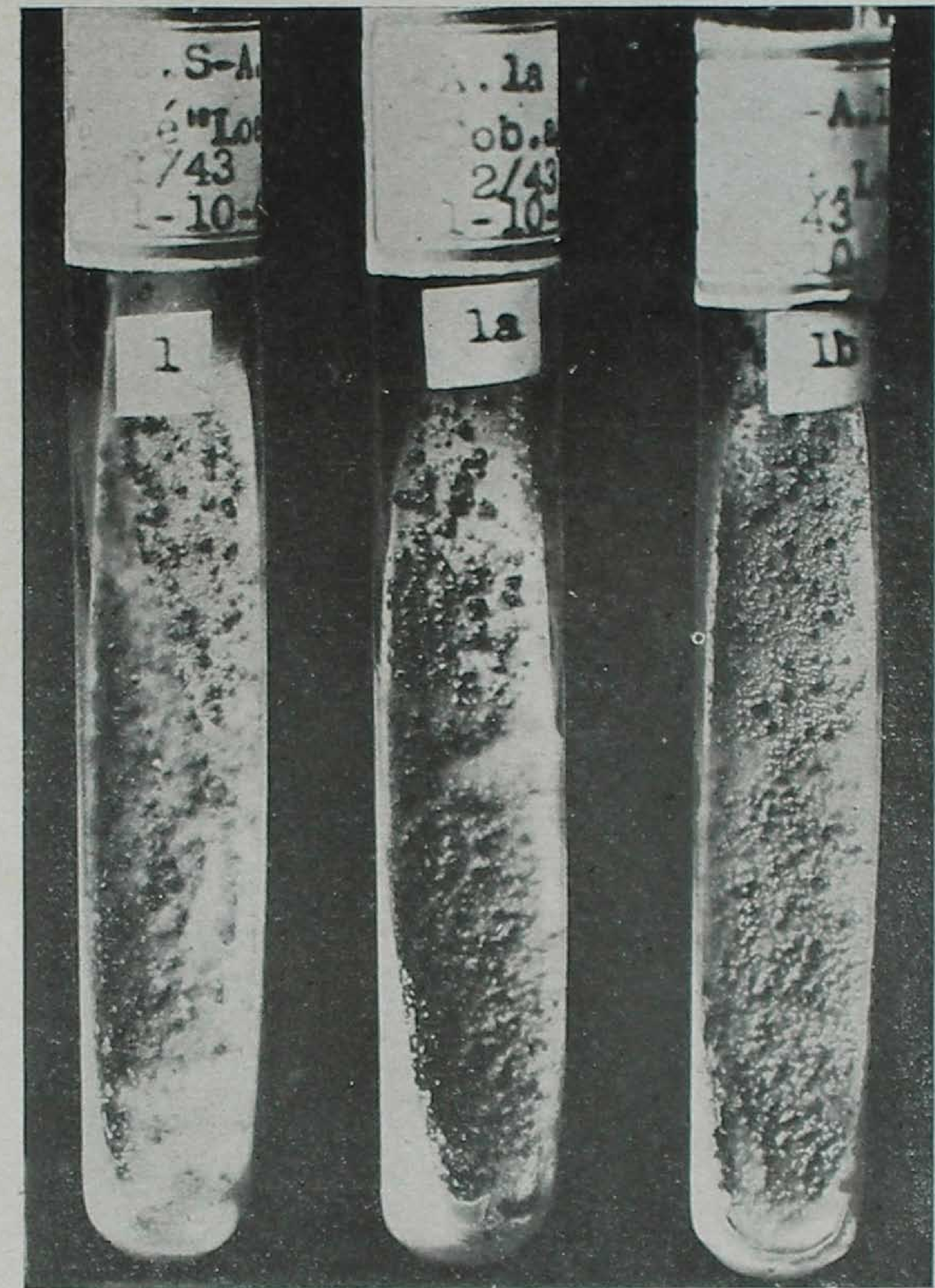

sã̃o as de n..$^{\circ}$, la e 5, e está sendo ensaiada a "Leprolina mista: $1+5$ ". Os números dos antígenos correspondem aos números das culturas que lhes serviram de matéria prima.

Manufactura das Leprolinas - O método primitivo de fabríco dos antígenos é o que tem dado melhores resultados. O lisado da Leprolina preparado pelo Químico Humberto Cardoso, do Instituto Oswaldo Cruz, e o "Hansenlisado" (lisado da Cultura "José 1a" misturado ao do B. subtilis) preparado pelo bacteriologista chileno Dr. A. Arriagada VAlenzuela, se 
Souza-Araujo: Acção das Leprolinas nos males perfurantes plantares 257

mostraram inactivos tanto para as intradermo-reaç̧ões como para os ensaios terapêticos. A actuail manufactura obedece às seguintes fases:

1. Selecção duma cultura exuberante, em Loewenstern e seu repique em balôes de caldo glicerinado a $5 \%$ (balões de 100 ou de $1.000 \mathrm{~cm} 3$ ). Estamos usando culturas que sofreram a acção da Penicilina e se tornaram mais exuberantes .

2. Incubação a 37. $\mathrm{C}$. até que se formem nos balões denso deposito dos véus (20 a 30 dias) e com véu permanente, sem turvação do meio, como se vê noz balões da Figura II.

3. Adição de ácido fênico puro na proporção de 0,5\% do cald̉o. Agitar os balões e deixá-los na geladeira durante um a três dias.

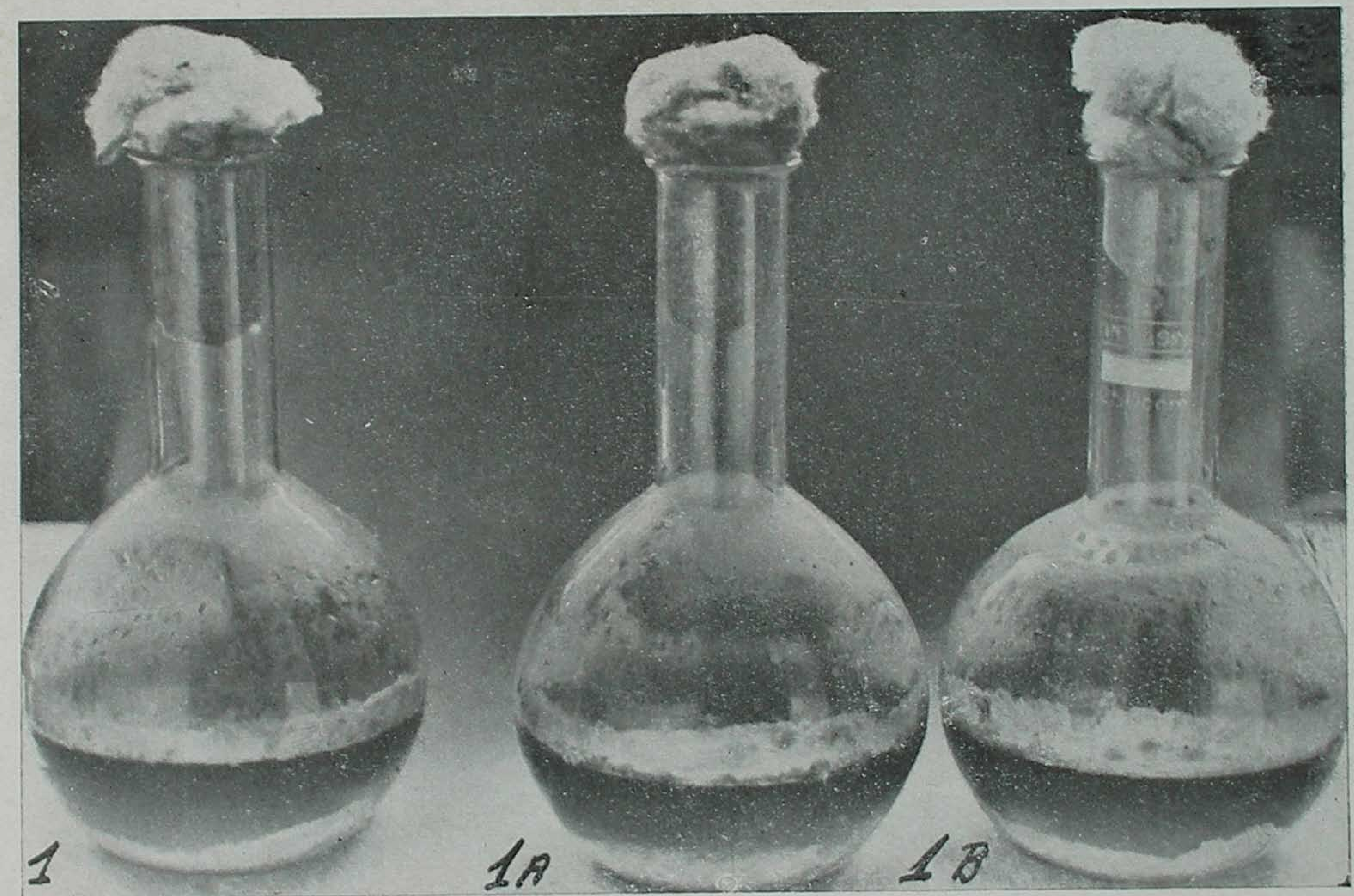

Fig. II - Cultura "José 1 " e retroculturas la de cobaia e 1 b de rato branco, em caldo glıce nado a $5 \%$, após 30 dias de incubação a $37^{\circ} \mathrm{C}$., mostrando os véus e depósitos. O meio conserva-se límpido. Ad:e onado o fenol a $0,5 \%$ vão para o agitador

4. Agitaçã e transferência da cultura para frascos especiais, contendo 50,0 grs. de pérolas de porcelana esterilizadas, os quais são amarrados no agitador electrico.

5. Ag tação ininterrupta durante pelo menos 10 dias. 
6. A cultura total, completamente homogenizada, é a Leprolina bruta, como se vê abaixo, na figura III.

7. A Leprolina bruta é diluida na proporção de 10 para $100 \mathrm{~cm} 3 \mathrm{em}$ água destiladá esterilizada e fenicada a $0,5 \%$. (Fig. IV).



Fiig. III - Balões com Leprolinas brutas depois duma noite de repouso na geladeira, após retiradas do agitador. Nos fundos dos balões se veem os bacilos reduzidos à poeira. O líquido sobrenadante apresenta-se leitoso ou côr de ambar, conforme a cultura usada, si mais ou menos cromogênica.

8. Distribuição asséptica em ampolas de 2 ou de $5 \mathrm{~cm} 3$ ou em frascos tipo "Insulina", para os diferentes usos, se intravenoso, intradérmico ou intramuscular nas bordas das úlceras perfurantes plantares.

Acção terapêtutica das Leprolinas - Os trabalhos publicados sôbre o em. prego das Leprolinas em intradermo-reacções e como agente terapêutico geral da lepra estão a merecer uma revisão ou rectificação. Entretanto, como agente terapêutico local, nos males perfurantes plantares lepróticos, a grande eficácia 
das Leprolinas está comprovada e merece ampla divulgação. E' esse o tema deste informe sumário e de três outros trabalhos que serão apresentados ao Congresso de Lepra de Havana, pela Delegação do Estado de Minas Gerais.



b'ig. IV - Leprolinas c.luidas a $10 \%$ em água Merthiolatada a $1: 10.000$ (N.o 1) e água renicada a $0,5 \%$ (Balão n. ${ }^{\circ}$ 2), prontas para distribuição em ampôlas. Nessa diluição a $10 \%$ são usacias na dose de 0,2 a $1,0 \mathrm{~cm} 3$ por via intravenosa ou de 1 a 5 cm3 por via intramuscular, intranodular ou intradérmica, de $4 \mathrm{em} 4$ dias.

Foi o Dr, José Mariano (Comunicação à Academia Nacional de Medicina a 19-4-45) quem primeiro assinalou o efeito cicatrizante das Leprolinas sobre úlceras perfurantes plantares e outras, em leprosos. A minha experiência pessoal é pequena: tenho apenas cinco observações que serão resumidas adiante. No Hospital-Colonia "Curupaity" (Distrito Federal) os Drs. 
Pimentel e Oliveira Lima, têm maior número de casos curados com as Leprolinas. Idêntica experiência me tem sido comunicada de vários outros leprosários do país. Do modelar leprosário paulista Asilo-Colonia "Aymorés", de Baurú, o Dr. Tupy Pereira Cassiano mandou-me, gentilmente, o seguinte relatório :

"Tratamento do mal perfurante plantar, em doentes de lepra, com a Leprolina Souza-Araujo.

\section{Observações:}

1. Virginia F., branca, italiana, 65 anos, casada, domestica. Leprosa há 19 anos: Forma lepromatosa completa. Mal perfurante no terço anterior da região plantar direita há 3 anos. Tratamento: injecções locais de Leprolina no dia 6-10-46: 1cc. Mais 7 sessões de injecções focais e périfocais de 1,5 c.c., intervaladas de 4 dias. Total 11,5 c.c. Alta : 8 11-46: lesão cicatrtizada. Reabriu pequena lesão 7 meses depois. Novas injecções. Cicatrização.

2. Emilia P., branca, brasileira, solteira, 21 anos, domestica. Leprosa há 13 anos: Forma incaracterisitica nervosa. Mal perfurante na face plantar do grande artelho direito, há 3 anos. Tratamento: injecções focais em 3-6-46: 1 c.c. e mais 5 sessões de 2 c.c. cada uma e com intervalos de 3 dias. Total 11 c.c. Alta : 25-6-46: lesão cicatrizada. Cura mantida: 15-3-48.

3. Elza G., branca, brasileira, solteira, 21 anos, domestica. Leprosa há 7 anos: Fórma incaracteristica cutâneo-nervosa. Mal perfurante plantar nos dois grandes artelhos há 30 meses. Tratamento: injecções focais de Lepro lina em 3-6-46: 1 c.c. em cada lesão e mais 3 sessões de 1 c.c. em cada lesão, com intervalos de 3 dias. Total 8 c.c. Alta: 20-6-46, com as lesões cicatrizadas. Cura mantida: 15-3-48.

4. Francisca V., branca, brasileira, 45 anos, casada, domest ca. Leprosa há 9 anos: Fórma lepromałosa completa. Mal perfurante plantar terço anterior do pé esquerdo, há 2 anos. Tratamento: injecções focais de Leprolina em 9-8-46: 1 c.c. e mais 5 sessões de 1 c.c. intervaladas de 4 dias. Total 6 c.c. Alta em 3-9-46: Lesão cicatrizaáa. Cura mantida: 15-4-48

5. Lázara F. de O., branca, brasileira, 34 anos, solteira, domestica. Leprosa há 17 anos: Fórma incaracteristica nervosa. Mal perfurante do terço anterior do pé esquerdo, há 3 anos. Tratamento: injecções focais de Leprolina em 6-4-46: 1 c.c. e mais 5 sessões de 2 c.c. cada 4 dias. T'otal 11 c.c. Alta: 6-5-47: lesão cicatrizada. Cura mantida: 15-3-48.

6. Tarcilia M. Q., branca, brasileira, 47 anos, casada, domestica. Leprosa há 21 anos: Fórma incaracteristica nervosa. Mal perfurante plantar do grande artelho esquerdo. Tratamento: injecções focais de Leprolina em 6- 
10-46: 1 c.c. e mais 7 sessões de 1 c.c. cada 4 dias. Total 8 c.c. Alta em 30 10-46: Lesão cicatrizada. Recidiva pequenina lesão em 6-6-47. Nova injecção: Cicatrização: 15-3-48.

7. Antonia V., branca, brasileira, 29 anos, solteira, domestica. Leprosa há 23 anos: Fórma lepromatosa completa. Mal perfurante plantar terço anterior do pé esquerdo. Tratamento: injecções focais de Leprolina em 3-9-46: 1 c.c. e mais 5 sessões de 1 c.c. cada 4 dias. Total 11 c.c. Alta em 289-46: Lesão cicatrizada. Houve pequena lesão recidivante em 14-7-47. O Raio X revelou grave lesão óssea: 15-3-48.

8. Ana F. de L., branca, brasileira, 54 anos, viuva, domestica. Leprosa há 20 anos: Fót'ma incaracteristica cutâneo-nervosa. Mal perfurante plantar no calcanhar esquerdo há 4 anos. Tratamento: injecções focais de Leprolina em 20-9-46: 1 c.c. e mais 8 sessões de 1 c. c. cada 4 dias. Total 9 c.c. Alta em 27-10-46: Lesão cicatrizada. Houve recidiva, pequena lesão, em 6-2-47. O Raio X. revelou grave lesão óssea: 15-3-48.

9. Antônio M. do C., branco, brasileiro, 46 anos, solteiro, lavrador. Leproso há 17 anos: Fórma lepromatosa completa. Mal perfurante plantar grande artelho direito há 1 ano. Tratamento: injecções focais de Leprolina em 9-9-46: 1 c.c. e mais 3 sessões de 2 c.c. cada 4 dias. Total 7 c.c. Alta: em 6-10-46: Lesão cicatrizada. Cura mantida em 15-3-48.

10. Herminio S. dos S., branco, brasileiro, 50 anos, casado, lavrador. Leproso há 14 anos: Fórma lepromatosa completa. Mal perfurante plantar borda do pé direito há 2 anos. Tratamento: injecções focais de Leprolina em 20-7-46: 1 c.c. e mais 4 sessões de 2 c.c. cada 4 dias. Total 9 c.c. Alta: em 20-9-46: Lesão cicatrizada. Cura mantida: 15-3-48.

11. Clemente F. de M., branco, brasileiro, 50 anos, solteiro, lavrador. Leproso há 6 anos: Fórma leprománsa completa. Mal perfurante plantar no grande artelho esquerdo há 1 ano. Tratamento: injecções focais em 26-7-46: 1 c.c. e mais 2 sessões de 1 c.c. cada 4 dias. Total 3 c. c. Alta em 15-8-46: Lesão cicatrizada. Cura mantida : 15-3-48.

12. José A., branco, brasileiro, 28 anos, solteiro, lavrador. Leproso há 11 anos: Fórma lepromatosa completa. Mal perfurante plantar grande artelho esquerdo há 1 ano. Tratamento: injecções focais de Leprolina em 9-9 46: 1 c. c. e mais 3 sessões de 2 c.c. cada 4 dias. Total 7 c.c. Alta em 23-9-46: Lesão cicatrizada. Honve recidiva, pequena lesão, em 25-12-46. O Raio X revelou grave lesão óssea: 15-3-48.

13. Juvenal R., branco, brasileiro, 44 anos, viuvo, lavrador. Leproso há 7 anos: Fórma lepromatosa completa. Mal perfurante plantar no terço an- 
terior de ambos os pés há 2 anos. Tratamento: injecções focais de Leprolina em 12-9-46: 1 c.c. em cada lesão e mais $\&$ sessões de 2 c.c., cada 4 dias e em cada lesão. Total 17 c.c. Alta em 5-10-46: Lesões cicatizadas. Cura mantida, 15-3-48.

14. Delfino A. de L., branco, brasileiro, 55 anos, casado, laviador. Leproso há 23 anos: Fórma incaracteristiọa nervosa. Grande mal perfurante plantar no terço anterior do pé esquerdo há 2 anos. Tratamento : injecções focais de Leprolina em 13-7-46:1 c.c. e mais 6 sessões de 2 c.c. cada 4 dias. Total 13 c.c. Alta em 14-8-46: Lesão cicatrizada. Cura mantida: 15-3-48.

15. José F. fo., branco, brasileiro, 47 anos, viuvo, carroceiro. Leproso há 14 anos: Fórma lepromatosa completa. Mal perfurante plantar no terço anterior do pé esquerdo. Tratamento: injecções focais de Leprolina em 139-46: 1 c.c. e mais 1 de 2 c.c. em 19-9-46. Total 3 c.c. Alta em 5-10-46: Lesão cicatrizada. Cura mantida: 15-3-48.

16. João F., preto, brasileiro, 28 anos, solteiro, lavrador. Leproso há 9 anos: Fórma lepromatosa completa. Mal perfurante na face plantar do grande artelho esquerdo há 1 ano. 'Tratamento: injecção focal de Leprolina em 9-10-46; 1 c.c. e mais 3 sessões de 2 c.c. cada 4 dias. Total 7 c.c. Alta em 25-10-46: Lesão cicatrizada. Cura mantida: 15-3-48.

17. Alberto S. G., português, branco, 51 anos, casado, lavrador. Leproso há 10 anos: Fórma lepromatosa completa. Mal perfurante plantar do grande artelho direito há 1 ano. Tratamento: injecções focais de Leprolina em 5-10-46: 1 c.c. e mais 2 sessões de 2 c.c. cada 4 dias. Total 5 c.c. Alta em 21-10-46: Lesão cicatrizada. Cura mantida: 15-3-48.

18. Domingos M., branco, brasileiro, 63 anos, casado, serrador. Leproso há 11 anos: Fórma incaracteristica nervosa. Mal perfurante plantar do grande artelho direito. Tratamento: injecções focais de Leprolina em 29 10-46: 1 c.c. e mais uma de 2 c.c. a 3-11. Total 3 c.c. Alta em 10-11-46: Lesão cicatrizada. Cura mantida: 15-3-48.

19. José C., branco, brasileiro, 67 anos, casado, lavrador. Leproso há 14 anos: Fórma tuberculoide cutâneo nlevicsa. Mal perfurante plantar no terço anterior do pé direitio há 1 ano. Tratamento: injecções focais de Leprolina em 20-8-46: 1 c.c. e outra de 2 c.c. a 25-8. Alta em 3iJ-8-46: Lesão cicatrizada. Cura mantida: 15-3-48.

20. Alencar M., branco, brasileiro, 33 anos, casado, lavrador. Leproso há 8 anos: Fómma tuberculoide cutâneo-nertosa. Mal perfurante plantar do grande artelho esquerdo há 2 anos. Tratamento: injecções focais de Lepro- 
lina em 23-8-46: 1 c.c. e mais 3 sessões de 2 c.c. cada 4 dias. Total 7 c.c. Alta em 10-9-46: Lesão cicatrizada. Cura mantida: 15-3-48.

21. João D., branco, brasileiro, 43 anos, solteiro, oleiro. Leproso há 12 anos: Fórma incaracteristica nervosa. Mal perfurante plantar junto á articulação do grande artelho direito, há 3 anos. Tratamento: injecções focais de Leprolina em 15 10 -46: 1 c.c. e mais 3 sessões de 2 c.c. cada 4 dias. Total 7 c.c. Alta em 30 10-46: Lesão cicatrizada. Cura mantida: 15-3-1948.

Nota: - Todas as injecções de Leprolina provocaram reacções gerais, algumas bastante intensas. Baurú, 22 de julho de 1947".

Pelo Relatório complementar do Dr. Tupy Pereira Cassiano, datado de 15 de Março corrente, verifica-se que dos 21 leprosos por ele tratados com a Leprolina, 18 , ou sejam $85,7 \%$, permanecem curados dos seus males perfurantes plantares após 18 meses em média, das altas. O mais notável é que esse grande sucesso terapêtico foi obtido num prazo muito curto: 23 dias em média para os 18 doentes curados. Assim também é digno de nota a pequena dose de antígeno gasto: em média $7,7 \mathrm{~cm} 3$.

Sabendo-se que o mal perfurante plantar é o sintoma da lepra mais rebelde á cura, retendo no leito o leproso por longo tempo ou o impossibilitando para qualquer actividade rural, um tratamento que o cure em menos dum mês e com uma despesa inferior a dez cruzeiros de medicamento, representa para os leprosários um verdadeiro "Boon", na accepção americana de benção.

\section{Observações pessoais}

1. A. M., branco, biasileiro, 30 anos, casado, militar. Ao 1.० exame clínico, em 8-10-42 era um caso L2-N1. Apresentava além das lesões cutâneas mal perfurante no centro da planta do pé direito, datando de 1 ano, tendo sido precedido de grande calosidade. Esse pé era insensivel desde 1929, em consequência dum ferimento na região maleolar. A electrocoagulação da úlcera não deu resultado. Em 7-5-43 submeteu-se à operação de LÉRICHE (Dr. Pedro Míura) e curetagem da úlcera. A radiografia não mostrou lesão óssea. A úlcera cicatrizou dentro de 30 dias e reabriu meses após, porém menor. De 1944 a 45 se formaram mais duas úlceras, uma na planta do grande artelho e outra sobre abcesso no dorso do pé direito, entre o $4 .^{\circ}$ e o $5 .^{\circ}$ artelhos.

Leprolinoterapia - 28-3-1946: 1. a injecção de Leprolina: 1,5 c.c. nas úlceras e 1,5 c.c. no dorso de pé. Reacção: cefaléia, calafrios e febre alta $\left(39 .^{\circ}\right.$ a $40 .^{\circ}$ C. $)$, durante 4 dias. 4 4: As lesões apresentam bom aspecto. 2.a 
aplicação: 2 c.c. nas lesões plantares e 1,5 c.c. no dorso do pé. 11 4 : 3. ${ }^{\text {a }}$ aplicação: 2 c.c. nas lesões plantares e 1 c.c. no dorso. 30-4: $4 .^{\mathrm{a}}$ aplicação: 4 c.c. nas úlceras plantares e no nodulo dorsal.

Resultado: desaparecimento da calosidade das bordas das úlceras, expulsão de matéria purulenta e fragmentos de ossos, cicatrização das úlceras plantares e formação dum nodulo dorsal sôbre as articulações do $3 .^{\circ}$ e $4 .^{\circ}$ ar telhos, correspondente à maior úlcera plantar cicatrizada. Ligeiro encurtamento do 3. ${ }^{\circ}$ artelho. Pausa de 3 meses. Em Agôsto e Setembro tomou 2 pequenas injecções. A 26-9 expulsou fragmentos de osso cariado da úlcera dorsal do $4 .^{\circ}$ artelho. Nova pausa longa de qualquer tratamento. 9-1-1947: As 4 úlceras tratadas com a Leprolina estão cicatrizadas e surgiu uma nova, debaixo do $5 .^{\circ}$ artelho direito, que cicatrizou logo com as injecções do antí geno. Em Abril reincidiu o mal perfurante do grande artelho e surgiu novo nodulo dorsal do pé. Durante 3 meses injectamos Promin nessas lesões sem resultado notável. De 8-12-47 a 20-3-48 fizemos 10 pequenas injecções focais de Leprolina nessas lesões e hoje ambas estão melhores que nunca, porém ainda não completamente curadas.

2. Augusta B., branca, brasileira, 38 anos, solteira, domestica. Em 1933 era um caso C2 (ainda dominava a classificação de Manila), com poucos lepromas esparsos pelos membros. Tratamento ecléctico até 1934. Passou 9 anos sem tratamento de consolidaçăo. Em 1944 era L1-N1, com males perfurantes plantares nos dois grandes artelhos, seguidos de outros no pequeno artelho direito e $4.0^{\circ}$ esquerdo. Tratamento fisioterápico com resultado aleatório. Em 3-4 e 28-8-45 extirpações de vários fragmentos osseos das lesões tanto, estão hoje completamente curadas.

Leprolinoterapia - Depois dalgumas pequenas injecções intravenosas de Leprolina, que lhe produziram reaç̧ão geral moderada, iniciei o tratamento dos seus males perfurantes plantares com injecçōes focais, da mesma. De 12-12-45 a 10-3-1948 tomou $28 \mathrm{~cm} 3$ desse produto nas lesões plantares e outro tanto por via intravenosa. Por ter sido muito irregular o tratamento, houve no correr dele melhoras e pioras das lesões ulcerosas, as quais, entretanto, estão completamente curadas.

3. Luiz F. P., branco, brasileiro, 54 anos, casado, lavrador. A sua doença começou por dormência no maleolo direito em 1932 e polyneurite em 1934. Ao meu 1. ${ }^{\circ}$ exame em 21-7-29 era um caso L2-N2. Esteve hospitalizado entre 1939 e 40 e em 41 submeteu-se a um tratamento eclectico (chaulmoogra e fisioterapia) regular, resultando o desaparecimento das lesões cutâneas activas. Tal tratamento nâo impediu o aparecimento de úlceras perfurantes no terço anterior da planta e do grande artelho do pé esquerdo. Iniciado em 
31-12-45 o tratamento desses males com injecções focais e compressas de Leprolina, em 21-3-46 a sua cicatrização era completa.

4. Maria R. da S., branca, brasileira, 54 anos, viuva, domestica. Ao meu 1. exame em 26-1-35 era um caso L3. Em 1936 teve violenta reacção leprótica que agravou o seu estado. Depois dum tratamento eclectico intensivo desapareceram as lesôes cutâneas. Abandonado o tratamento por alguns anos, em 1947 voltou a L3-N1 com mal perfurante plantar no grande artelho esquerdo, com grande edêma do pé e perna. Com 5 aplicações focais de Leprolina, na dose total de $9,5 \mathrm{~cm} .3$, no fim de 2 e $1 / 2$ meses e após quédas de esp _ssas crôstas, essa úlcera cicáirizou e o edêma desapareceu.

5. Francisco C. dos S., preto, brasileiro, 50 anos, casado, pedreiro. Ao meu $1 .^{\circ}$ exame em $25-1-36$ era um caso N2. Ao 2. ${ }^{\circ}$ exame, nove anos depois, em 18-7-45, era L2-N2, com dois extensos males perfurantes plantares nos calcanhares e uma úlcera leprótica no maleólo esquerdo. Com 3 aplicações rocais de Leprolina nas úlceras plantares, entre 28-1 e 8-4-46, com apenas $4 \mathrm{~cm} 3$ do produto. essas lesões cicatrizaram completamente, como veritiquei em 19-8-46 e confirmei em 19-1-48, tornando o paciente válido.

Verificada a eficácia das Leprolinas nos males perfurantes plantares, distribuí grandes partidas desse produto a vários leprosários para uma experiência em maior escala. Do leprosário "Padre Damião", de Minas Gerais, me vieram palavras muito animadoras num documento oficial cuja fotocópia dou abaixo.

Esse documento é mais significativo que o meu julgamento. Indagando do autor da comunicação o número dos doentes tratados, em telegrama N. 255 de Ubá, de 17 do corrente, o Dr. Raymundo Da Gloria Caldeira me informa: "Tenho cinquenta observações mal perfurante tratado leprolina pt Cura sem recidiva quat'nta seis casos." e que ia remeter ao Congresso de Havana um trabalho sôbre isso. O Dr. CALDEIRA obteve $92 \%$ de curas!

Da França também me veiu uma confirmação da nossa experiência. Em carta de 17-12-47 o Director da "Léproserie de Valbonne", Pont St-Esprit, Gard, Mr. A.lbert Delord informa:

"Je veux encore vous signaler le résultat remarauable obtenue par votre vaccin sur notre malade Algérien dont le mal perforant plantaire, vieux de plus de dix ans est totalement guéri."

Comprovada a acção terapêutica da Leprolina, na lepra, não interessa, no momento, saber-se se ela age como antigeno especifico ou não-especifico. 


\section{SERVIÇO PUBLICO DO ESTADO DE MINAS GERAIS SERVICQO DE DEFESA CONTRA A LEPRA}

BELO HORIZONTE, 23 DE JUnhO DE 1047.

Prezado Souza Araujo.

Realizou-se śábado, 21, em Ubá, na colônia Padre Damião, uma sessão extraordinária da Sociedade Mineira de Leprologia.

Estiveram presentes 19 leprólogos, dentre
eles, o nosso caro amigo Risi.

Nessa sessão foram apresentados, pelo Diretor da Colônia, Raimundo da Glória Caldeira, vários casos de males perfurantes, tratados pela Leprolina Souza Araujo. Alguns completamente cicatrizados em espaço de tempo curto. Todos os outros muito melhorados.

O assunto foi vastamente, longamente, discutido, principalmente pelo Abrahão Salomão, Paulo Cerqueira, Orsini de castro, António Carlos Pereira e outros.

Chegou-se'à conclusão de que o método é magnifico, diante dos resultados que apresenta, sendo o mais rápido e o mais eficiente meio de tratamento.

cético, Mesmo eu que, como sabe, sou um mineirão bora nảo achasse 1 b́ico o mecanismo de de acão da Ieprolina, em face da natureza des melo são trofo-neurótica. tro-neurótica. De qualquer maneira, os resultados, nos casos de Ubá, sâo ótimos e aqui vai esta breve noticia e, com ela, o abraço do amigo de sempre.

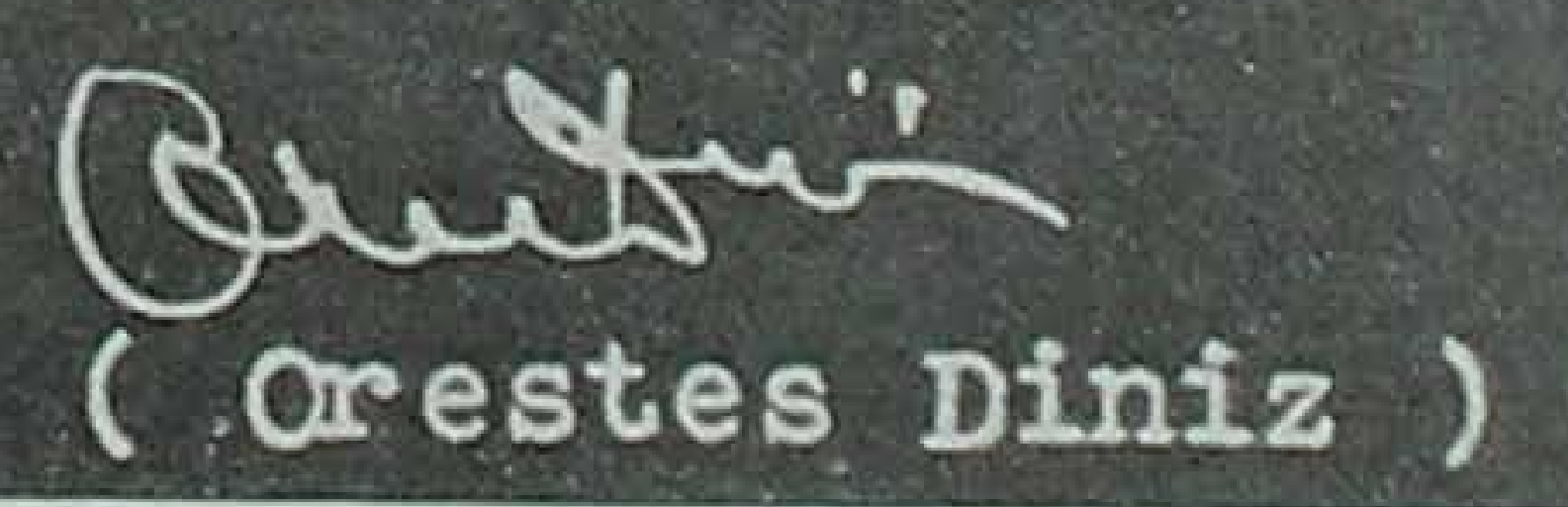


Interessa disseminar-se o seu uso nos leprosários de vários países para se obter a confirmação ou infirmação da experiência brasileira.

O Instituto Oswaldo Cruz fornecerá, gratuitamente, a Leprolina aos leprólogos desejosos de ensaiá-la.

Rio de Janeiro, 28 de Março de 1948.

\section{SUMMARY}

The A. remembers the history of his lepra-culture and the method he uses to prepare with it the anigen called Leprolin Souza-Araujo, giving photographic illustrations upon the subject.

The A. says that the results published about the general action of his Leprolin in leprosy must be revised or rectificated. But he says that the rapid action of his antigen upon perforant ulcers in lepers is consecrated by a large experience. He cured, in relatively short time, perforant ulcers in five lepers. Dr. Cassiano, from Baurú Leper Colony (S. Paulo) treated 21 of such cases. The median time of treatment was 23 days and the median dosage of Leprolin injected in each patient was $7.7 \mathrm{~cm} 3$. All lesions were cured. After 18 months observation three cases relapsed and 18 (or $85.7 \%$ ) remained cured.

Dr. Caldeira, Director of Padre Damien Leper Colony (Ubá, Minas Gerais) treated regularly with Leprolin 50 cases of severe perforant ulcers and obtained cure in 46 (or 92\%). In a special meeting held in Minas Gerais nineteen leprologists examined the cases of Dr. CALDEIRA and considered the results he have obtained as "magnifico", in the sense as "unic".

This experiment is being continued in various Brazilian leper colonies and the Author offers, graciously, his antigen to be tried also in foreing countries.

\section{REFERENCIAS}

1. Souza-Araujo, H. C. De

1942. Cultura cromogênica dum bacilo ácido-alcool resistente isolado de pus de lesão fechada de lepra humana. Memórias do Instituto Oswaldo Cruz, Tomo 37, Fascisculo 1, ano 1942, pp. 29-34, com 2 estampas.

2. Souza-Araujo, H. C. de..

1943. Preparo de Antigenos (Leprolinas Souza-Araujo) de culturas de bacilos ácidoálcool resistentes isolados de leprosos. Memórias do Instituto Oswaldo Cruz, Tomo 39, Fasciculo 3, Ano 1943, pp. 349-355.

3. Souza-Araujo, H. C. de..

1944. Culturas de bacilos ácido-álcool resistentes isolados de hematófagos infectados em leprosos. Evidências de se tratar do bacilo de Hansen. Memórias do Instituto Oswaldo Cruz. Tomo 40, Fasciculo 1, ano 1944, pp. 9-31. 